Department of Animal Science, University of Adelaide, Waite Agricultural Research

Institute, Glen Osmond, South Australia 5064, Australia

\title{
Breed differences and genetic parameters for melting point, marbling score and fatty acid composition of lot -fed cattle
}

\author{
A.E.O. Malau-Aduli, M. A.Edriss, B. D. Siebert, C. D. K. Bottema and W. S. Pitchford \\ Summary
}

Fatty acid composition, marbling score and melting point data collected between 1994 and 1996 were analysed. The data were from the adipose tissue of 764 Angus, Belgian Blue, Hereford, Jersey, Limousin, South Devon and Wagyu crossbred cattle slaughtered after lot-feeding at 500 days of age. The aim was to investigate sire -breed differences and to estimate heritability and genetic and phenotypic correlations. Signi ficant breed differences were found: Jersey crosses had the highest marbling score and Belgian Blue crosses had the lowest. Limousin crosses had the highest melting point and Jersey crosses the lowest. South Devon crosses had the highest proportion of stea rate and Jersey crosses the lowest. Desaturation indices in C16 and C18 fatty acids were highest in Jersey crosses and lowest in Limousin and South Devon crosses. In contrast, there were no breed differences in the proportions of palmitate, oleate, total s aturated, total mono-unsaturated fatty acids and elongation index. Heritability estimates of individual fatty acids and their summations, melting point and marbling were low to moderately low $(0.05-0.27)$. Strong genetic correlations of melting point and de saturation index in C16 fatty acids (-0.93), melting point and stearate $(0.62)$, marbling and stearate $(-0.71)$ and marbling and desaturation index in C18 fatty acids (0.62) were observed. Phenotypic correlation were generally low. The results imply that fat ty acids in the adipose tissue of lot-fed cattle have a moderately low heritability, hence genetic progress might be slow. 


\section{Introduction}

In order to produce cattle and meat products that are in demand by consumers, beef breeders are faced with the challenge of utilizing the diverse resources available to them. To accomplish these goals which include lean beef with less saturated fatty acid composition among others, breeders need information on breed differences and genetic parameters to develop effective breeding schemes (Marshall, 1994). Thus, estimates of heritability and genetic and phenotypic correlations are essential population attributes.

Breed differences in fatty acid composition of beef cattle have been repor ted between Brahman and Hereford (Huerta-Leidenz et al. 1993), Limousin and Jersey (Malau-Aduli et al. 1997a) and Hereford crossbreds (Siebert et al. 1998). In contrast, published reports on the heritability of fatty acids are scanty, and those available are mostly in pigs ( Bout et al. 1991; Cameron and Enser, 1991). Apart from a preliminary report on the heritabilities of triacylglycerol fatty acids from the adipose tissue (Malau-Aduli et al. 1998a), published estimates in beef cattle are to the authors' knowledge, not av ailable.

Marbling is currently an important factor used by the Australian beef industry to assign carcass quality of export beef (Baud et al. 1998). Melting point of fat in carcasses determines the hardness or softness, and significant sire-breed differences in the melting point of subcutaneous fat in steers have been reported (Perry et al. 1998). However, genetic and phenotypic correlations between melting point, marbling and fatty acid composition in beef cattle have not been reported. Therefore, the objective of this study was to present breed differences and genetic parameters for melting point, marbling score and fatty acid composition in beef adipose tissue of lot -fed cattle. 


\section{Materials and methods}

\section{Animals and management}

The study used animals from the Southern Crossbreeding Project located at the Struan Research Centre, and the J. S. Davies Gene Mapping Project located at Martindale, South Australia. The first project was designed to quantify differences between beef-cattle breeds with the aim of increasing the adoption of crossbreeding for beef production in Southern Australia (Rutley et al. 1995). Hereford dams were crossed to Angu s, Belgian blue, Hereford, Jersey, Limousin, South Devon and Wagyu sires. Calves were born in 1994, 1995 and 1996 and weaned between 250 to 300 days of age and horns were removed. Males were castrated at birth. Immediately after weaning, all cattle born in different years were biopsied as described by (Malau-Aduli et al. (1995). All 1994 cattle were transferred to Meningie Feedlot, South Australia, at about 500 days of age. Females were fed for approximately 90 days whereas males were fed for approximately 180 days prior to slaughter. They were given a ration containing a minimum of $60 \%$ grain and a maximum of $13 \%$ protein in the feedlot. The 1995 -born heifers entered Limerock Feedlot at Lower Light at approximately 350 days of age and were fed for 70 days whereas the steers were fed for 170 days, on average, after entering at approximately 530 days of age. The grain-based ration contained $12 \%$ protein and $10 \mathrm{MJ}$ metabolizable energy/kg of dry matter and was fed ad libitum. Heifers born in 1996 were also sent to Limerock Feedlot, at the same age as 1995 heifers but they were slaughtered at 100 days of age. They had access to a ration containing $12 \mathrm{MJ} / \mathrm{kg}$ dry matter with $13 \%$ protein. During growth and feedlot periods, all the necessary routine health care measures were observed. The 
experimental and feedlot environments are classified as 'Mediterranean', consisting of hot dry summers and mild wet winters (Griffin and McCaskill 1987). All cattle were slaughtered commercially in abattoirs in South Australia, New South Wales and Victoria. The resulting carcasses were sampled for fatty acid composition (as per Malau-Aduli et al. 1997a), intramuscular fat content (as per Malau-Aduli et al. 1996) and melting point (as per Malau-Aduli 1998) from the 12th to 13th rib interface. In total, the data used for this study comprised of 764 animals as shown in Table 1.

\section{Lipid extraction, fractionation and fatty acid methylation}

The methods used were those recommended by Christie (1989). Total lipids were extracted from samples of subcutaneous fat (approximately $0.1 \mathrm{~g}$ ) or muscle (approximately 1-2 g) with chloroform/methanol. For fatty acid analysis, the extracts were separated into triacylglycerol and phospholipid fractions by thin -layer chromatography on silica gel plates (Malau-Aduli et al. 1997b). The methyl esters of the first group of samples were prepared by base-catalysed procedures using sodium methoxide, later samples were methylated by acid-catalysed procedures using $1 \% \mathrm{H}_{2} \mathrm{SO}_{4}$ in dried methanol (Malau-Aduli et al. 1996).

\section{Fatty acid analysis}

Fatty acids were identified and quantified by gas -liquid chromatography using a Hewlett Packard gas chromatograph (model 5890) fit ted with fused silica capillary columns (either BP20 or BPX70, SGE, Melbourne, Australia). Hydrogen (6kPa head pressure) was used with the BP20 column and helium (30kPa) was used with the BPX70 column. 
Individual fatty acids were identified by comparison of retention times of samples with those of known reference standards. The integrated values (percentage of total for each component were calculated as a normalized area.

\section{Melting point determination}

Melting point was recorded as the 'slip point' determined according to AOCS (1993) except that instead of using a water bath, the samples were transferred to the wells (filled with water) of a DNA thermal cycler machine (Perkin Elmer Cetus Australia Ltd). A program was used that allowed the block to be raised at $1{ }^{\circ} \mathrm{C}$ per min from 25 to $50^{\circ} \mathrm{C}$ after a 5-min equilibration period at $25^{\circ} \mathrm{C}$. The capillary tubes were momentarily checked at each degree Centigrade rise in temperature then returned to the well. The temperature at which the fat 'slipped' upwards was recorded as the melting point.

\section{Marbling scores}

After slaughter, the chilled carcases were scored by accredited AUS -MEAT assessors in accordance with chiller assessment standards (AUS-MEAT 1995). The marbling score was determined by the visual comparison of the distribution and abundance of intramuscular fat in the Longissimus dorsi muscle with standardized photographs. All carcasses were scored at the 12th to 13th rib interface.

\section{Statistical analyses}

All data were initially analysed by least -squares analysis of variance using mixed models

procedure (Harvey 1990). Breed, sex, location, year and sire nested within breed were 
fitted in multivariable analyses using a sire model. Since location was not a significant source of variation, it was excluded from the model. Sex by year interaction was also fitted in the model. Variance and covariance components for different traits were computed using Harvey (1990). Intramuscular fat, C16 : 1, C18 : 1n7 and C18 : 2 had negative additive genetic variances, hence they were excluded from the analysis. All other estimates of variance and covariance components as well as bre ed and sex by year effects were fitted in an animal model to estimate heritability, genetic and phenotypic correlations by restricted maximum likelihood procedures (REML), using ASREML (Gilmour et al. 1998) multi-variable analysis. Least-squares means and standard errors were also estimated by ASREML uni-variable analysis using an animal model.

\section{Results}

Summary statistics of the unadjusted data on traits measured are presented in Table 2. Melting point of fat and marbling score were highly affected $(\mathrm{p}>0.01)$ by sire -breed and sex by year interaction (Table 3).

\section{Sire breed effects}

Progeny sired by Angus, Hereford, Jersey and Wagyu had marb ling scores higher than one, whereas progeny sired by the other sire-breeds scored less than one. Limousin crosses had the highest melting point of $40.8^{\circ} \mathrm{C}$ ( Table 3). Jersey crosses had the lowest melting point and the highest marbling scores $\left(37.5 \pm 0.37^{\circ} \mathrm{C}\right.$ and $1.43 \pm 0.06$, respectively), whereas Belgian Blue and Limousin crosses had the lowest marbling scores (0.87 and 0.88 , respectively). 
Proportions of individual fatty acids were not affected by sire -breed except stearate (C18 : 0) (Table 3). Jersey crosses had the lowest proportion of C18 : 0 (12.3\%). South Devon, Limousin and Hereford crosses had the highest proportions (14.1, 14.0 and 14.0\%, respectively). There were neither sire-breed differences in the summations of saturated (SFA) and mono-unsaturated (MUFA) fatty acids nor elongation index. However, desaturation indices in $\mathrm{C} 16\left({ }^{9}(\mathrm{C} 16)\right)$ and $\mathrm{C} 18\left({ }^{9}(\mathrm{C} 18)\right)$ fatty acids differed significantly $(\mathrm{p}<0.01)$. Jersey sires had the highest indices $(15.9$ for C16 and 77.0 for C18).

\section{Sex by year effects}

Sex by year interaction was a highly significant source of variation in the proportions of all individual fatty acids and their summations, as well as enzyme indices. A comparison of heifers in different years, shows that as the days in feedlot increased (70, 90 and 100 days, respectively), melting point increased $\left(37.5,38.8\right.$ and $40.3^{\circ} \mathrm{C}$, respectively) ( Table 3). In contrast, marbling scores decreased $(0.62,1.01$ and 1.36 , respectively). The same trends were evident for palmitate (C16:0), stearate (C18:0), oleate (C18:1n9) and SFA whereas the opposite was observed for MUFA and enzyme indices. However, there were no clearly defined patterns in steers.

\section{Heritability}

Commercially, two key factors for evaluating carcass quality are marbling and intramuscular fat. Marbling is a subjective measurement and depends on the assessor's 
judgement. Intramuscular fat content on the other hand, is an objective laboratory measurement. Melting point is an objective measurement which indicates the amoun $t$ of fat hardness. In this study, the additive genetic variance of intramuscular fat was negative hence its exclusion from further analysis. Heritability of marbling score was low $(0.09 \pm 0.08)$, whereas melting point had the highest heritability $(0.27 \pm 0.10)$ followed by SFA and desaturation index in C18 (0.22 \pm 0.06 and $0.19 \pm 0.02$, respectively) ( Table 4). The estimated heritabilities of individual triacylglycerol fatty acids were moderately low to low. The heritability of total SFA was higher than those of individual fatty acids (palmitate and stearate). Desaturation index had a higher heritability in C18 fatty acids $(0.19 \pm 0.02)$ than in C16 fatty acid $(0.13 \pm 0.08)$. Total MUFA also had a low heritability of $0.14 \pm 0.01$ (Table 4 ).

\section{Genetic and phenotypic correlations}

Genetic correlations of melting point with fatty acids and enzyme indices were all higher than phenotypic correlations except with ${ }^{9}(\mathrm{C} 18)$ (Table 5). There were positive phenotypic correlations between melting point and stearate and SFA. In contr ast, melting

point had negative correlations with ${ }^{9}(\mathrm{C} 16),{ }^{9}(\mathrm{C} 18)$ and MUFA $(0.41,0.41,-0.40$, -0.35 and -0.36 , respectively). There were also low phenotypic correlations between melting point and palmitate and oleate $(0.20$ and -0.21 , respectively). There was no phenotypic relationship between melting point and elongation index ( Table 5). Genetic correlations of melting point with individual fatty acids were medium to high ranging from 0.26 to 0.62 . Melting point was also positively correlated with SFA and negatively with MUFA ( 0.36 and -0.38 , respectively). The degree of association between melting 
point and ${ }^{9}(\mathrm{C} 16)$ was very strong and negative $(-0.93)$, and moderate to low with ${ }^{9}(\mathrm{C} 18)$ and elongase $(-0.14$ and 0.39 , respectively). There were very low phenotypic correlations between marbling and all individual fatty acids and enzyme indices, ranging from -0.01 with SFA to 0.09 with ${ }^{9}(\mathrm{C} 16)$. In contrast, genetic correlations were generally higher (Table 5), ranging from -0.01 to -0.71 . Specifically, the genetic correlation between marbling and palmitate was negative and poor $(-0.11)$, but it was negatively highly correlated with stearate (-0.71). There was a medium genetic relationship (0.37) between marbling and MUFA (C18 : 1n9). There was also a negative genetic correlation with SFA (-0.42) and positive genetic correlation with MUFA (0.45). With regard to desaturation and elongation indices, marbling had high positive correlations of 0.60 with ${ }^{9}(\mathrm{C} 18)$, and 0.46 with ${ }^{9}(\mathrm{C} 16)$, but a very weak correlation with elongation index (-0.01) (Table 5).

Melting point and marbling were negatively genetically correlated $(-0.48)$, but phenotypically, there was no relationship between them (Table 6). There was a positive genetic correlation between palmitate and stearate $(0.67)$ whereas oleate and the other individual fatty acids were highly negatively correlated ( -0.81 and -1.00$)$. Highly negative phenotypic and genetic correlations between SFA and MUFA were also observed. There were positive genetic correlations between ${ }^{9}(\mathrm{C} 16)$ and ${ }^{9}(\mathrm{C} 18)$, and ${ }^{9}(\mathrm{C} 18)$ and elongation index, whereas elongation index and ${ }^{9}(\mathrm{C} 16)$ were poorly correlated (Table 6).

\section{Discussion}


Melting point of fat, marbling and fatty acid composition are important attributes of beef quality. This study investigated sire-breed differences and interaction between sex and year of sampling, as well as estimates of genetic parameters for these traits in lot -fed cattle.

\section{Sire breed differences}

The melting point of long-chain fatty acids and their esters are related to the arrangement of molecules within the crystal, whereas those of unsaturated fatty acids depend on the nature of the unsaturated group, configuration, number and relative position of the double bond (Litchfield 1972). It follows that melting point increases as the proportion of SFA increases, whereas an increase in the proportion of u nsaturated fatty acids is accompanied by a decrease in melting point (Gurr and Harwood 1991). Significant sire-breed differences were observed in melting point (Table 3). Jersey crosses had the lowest melting point and Limousin crosses had the highest. It has been demonstrated ( Siebert et al. 1998) that Jersey $\times$ Hereford crosses had the highest proportion of palmitoleate (16 : 1), oleate (18: 1n-9) and total MUFA in a comparison of seven breeds of crossbred cattle at weaning. Given that the melting point of $16: 1\left(1^{\circ} \mathrm{C}\right)$ and $18: 1 \mathrm{n}-9\left(16^{\circ} \mathrm{C}\right)$ are low relative to SFA like palmitate $\left(16: 0,61^{\circ} \mathrm{C}\right)$ and stearate $\left(18: 0,70^{\circ} \mathrm{C}\right)$, the fats of Jersey crosses are softer with low melting points than those of Limousin crosses. Perry et al. (1998) also found significant sire-breed differences in melting point and fatty acid composition in steers. In carcass-grading systems, marbling score is frequently used to assess the likely intramuscular fat content, which is then thought to be related to eating quality (Baud et al. 1998). Jersey crosses had the highest marbling score whereas 
Limousin and Belgian Blue crosses had the lowest (Table 3). This observation agrees with a similar report by Cundiff et al. (1998) in which the Limousin was described as a high meat-yielding but low intramuscular fat-containing breed and the Jersey as a low meat-yielding but high intramuscular fat-containing breed. It can be hypothesized that Jersey crosses being early-maturing, reach physiological maturity and begin to deposit intramuscular fat earlier, than the late-maturing Limousin crosses of the same age. Thus, marbling and maturity pattern are related and breed variation occurs. Johnson (1987) in a study of marbling in beef, reported that the early maturing Angus and Hereford had more intramuscular fat than the late-maturing Charolais $\times$ Illawarra cattle. Significant breed differences in marbling scores have also been re ported between Santa Gertrudis and Herefords (Thornton et al. 1974). A recent sire-breed comparison of marbling scores in cattle showed that Jersey, Angus and Wagyu crosses had the highest marbling scores of 1.7, 1.6 and 1.6, respectively, whereas Limousin and Belgian Blue crosses had the lowest marbling scores of 1.0 each (Malau-Aduli 1998).

Significant sire breed differences were observed in the proportion of the individual fatty acid stearate (Table 3). Stearate is the second most abundant saturated fatty acid after palmitate in the adipose tissue accounting for $13-15 \%$ of the total fatty acids (Siebert et al. 1998). It is synthesized de novo from C16:0 by the chain-lengthening process of elongation by the elongase enzyme or from biohydrogenation of oleate $(18: 1 n-9)$ in ruminants. Jersey crosses had the lowest proportion of C18 : 0 whereas Limousin, South Devon and Hereford had the highest proportions. This implies that harder fats are expected from the latter sire-breeds due to higher melting points. The fact that there was no difference in elongation index between the sire -breeds rules out the de novo synthesis 
pathway as a source of variation. It therefore appears that biohydrogenation in the rumen is the most likely factor contributing to the observed difference. Siebert et al. (1996) and Malau-Aduli et al. (1997) have also reported breed differences in the proportions of C18 : 0 in lot-fed and pasture-fed cattle, respectively.

In highly fattened crossbred cattle, Siebert et al. (1996) found no significant difference in the SFA (mean 44\%) and MUFA (mean 54\%) in adipose tissue between Jersey $\times$ Hereford and European $\times$ Hereford cattle. The present data also showed that there were no sire-breed differences in the summations of SFA and MUFA (Table 3). However, significant sire-breed differences were observed in desaturation indices in C16 and C18 fatty acids with Jersey-sired progeny having the highest values. Desaturation of saturated to mono-unsaturated fatty acids is catalysed by ${ }^{9}$-desaturase enzyme when a double bond is inserted at the ninth carbon atom from the methyl end of the fatty acid chain. The present results agree with those of Malau-Aduli et al. (1997), Siebert et al. (1998), Deland et al. (1998) and Malau-Aduli et al. (1998a) that demonstrate significant breed differences in desaturation indices in cattle.

\section{Sex by year effect}

There were highly significant interactions between sex and year of sampling in all traits (Table 3). Steers were generally fed for longer periods than heifers in the feedlot, and in 1996, only heifers were sampled in this study. Although the significant interactions were not entirely surprising per se, it is hard to attribute them solely to either sex or year due to confounding. Suffice it to say however, that the sex differences observed did not follow the same pattern in different years. For example, despite the fact that steers were fed for 
longer periods than heifers in 1994, heifers still marbled more than steers ( Table 3), but in 1995, the reverse was observed. Differences in feedlot management practices from one year to the other could well be a contributing factor to the fluctuations in trends between sexes. The observed increase in melting point as the duration of $\mathrm{f}$ eedloting of heifers increased suggests that a high proportion of saturated fatty acids was accumulating in the adipose tissue. As expected, the proportion of MUFA was lowered, hence a decrease in marbling scores and desaturation indices. This is in contra st to previous reports of increased MUFA and decreased SFA as age increased (Hecker et al. 1975; HuertaLeidenz et al. 1996; Malau-Aduli et al. 1997; Perry et al. 1998). However, in steers across years, the results in this study agree with previous studies cited above.

\section{Heritability estimates}

Genetic parameter estimates for beef cattle traits have been reviewed several times (Mohiuddin 1993; Davis 1993; Koots et al. 1994a, b). However, none of these reviews had any heritability estimates for fatty acid composition. In a preliminary report on fatty acids in the adipose tissue, Malau-Aduli et al. (1998a) obtained heritability estimates of 0.15, 0.16 and 0.00 for saturated, mono-unsaturated and polyunsaturated fatty acids, respectively, in weaner cattle. The data in this study also confirm the low to moderately low heritability estimates (Table 4). The implication is that genetic progress would be slow since the contribution of additive genetic variance to the phenotype is less than the environmental component. In contrast, moderate genetic gains would be realized for melting point due to its moderate heritability estimate of 0.27 ( Table 4). Therefore, by selecting sires with high or low breeding values for melting point, breeders would be able 
to increase or decrease the hardness of fat produced by beef cattle. The low heritability of marbling indicates that paying more attention to environmental factors such as feeding regime and/or energy content of feeds may improve marbling much faster than genetic selection.

\section{Genetic and phenotypic correlations}

There were strong correlations among and between individual fa tty acids, their summations, desaturation indices, marbling and melting point (Tables 5 and 6). Generally, genetic correlations were stronger than phenotypic correlations. This observation agrees with the report of Koots et al. (1994a) which demonstrated that phenotypic correlation estimates for many carcass quality traits as well as among reproductive traits were very poor. The positive correlations between melting point and stearate (C18: 0) and total SFA followed the expected trend because stearate has a melting point of $70^{\circ} \mathrm{C}$ and palmitate $61^{\circ} \mathrm{C}$ ( Gurr and Harwood 1991). Both fatty acids contribute the majority of total SFA in the adipose tissue. Thus, the higher their proportions in the adipose tissue, the harder the fat. This implies that selecting against these saturated fatty acids would indirectly lead to softer fats with higher proportions of unsaturated fatty acids. The strong negative correlation of -0.93 between melting point and desaturation index in C16 fatty acids ( Table 5) implies that selecting against hard fats would automatically lead to increa sed desaturation of saturated to mono-unsaturated fatty acids. However, the strength of this relationship between melting point and desaturation index is weak in $\mathrm{C} 18$ fatty acids. This could probably be due to the fact that $\mathrm{C} 18: 0$, the 
primary substrate that gets desaturated to $\mathrm{C} 18: 1 \mathrm{n}-9$, has a higher melting point than $\mathrm{C} 16$ : 0 (70 versus $61^{\circ} \mathrm{C}$, respectively).

Marbling score was strongly but negatively, correlated with stearate ( Table 6). This implies that animals with higher proportions of stearate in their adipose tissue, would have lower marbling scores than their counterparts with low stearate. Since marbling score and intramuscular fat content are positively correlated ( Baud et al. 1998), it is expected that such animals with low proportions of stearate are likely to be fatter. The positive but medium genetic correlation of 0.38 between marbling and oleate (C18: 1n -9) indicates that highly marbled tissues are likely to also have high proportions of oleate and total monounsaturates. This point is further buttressed by the highly positive genetic correlation between marbling and desaturation indices ( Table 5).

In conclusion, this study establishes the fact that sire-breed and sex and year interaction are important sources of variation in melting point, marbling score and fatty acid composition in the adipose tissue of beef cattle. It also demonstrates that fatty acids are low to moderately heritable. Furthermore, significant genetic correlations obtained between and among traits can be used in indirectly selecting for carcass quality attributes in lot-fed cattle.

\section{Acknowledgements}

This study was funded by the J. S. Davies Bequest Fund to the University of Adelaide, the South Australian Cattle Compensation Trust Fund and the Australian Development Cooperation and a scholarship from AusAID for A.E.O. Malau-Aduli. 


\section{References}

AOCS (American Oil Chemists' Society) 1993: AOCS Official Method,3 25.

AUSMEAT1995: Handbook of Australian Meat, 5th edn. Australian Meat and Livestock Corporation, Brisbane.112

Baud, S., Wade, C. M., Goddard, M. E., 1998: Aust. J. Agric. Res.49, 285.

Bout, J., Girard, P., Sellier, P., Runavot, J. P., 1991: Anim. Breed. Abstr.59, 162.

Cameron, N. D. \& Enser, M. B., 1991: Fatty acid composition in lipid longissimus dorsi muscle of Duroc and British Landrace pigs and its relationship with eating quality. Meat Sci.29, 295.

Christie, W. W., 1989: Gas Chromatography and Lipids.The Oily Press, UK. 307.

Cundiff, L. V., Dikeman, M. E., Koch, R. M., Crouse, J. D., Gregory, K.

E.,1988:Breeding for Lean Beef, Beef Research Progress Report No. 3,USDA,3 7.

Davis, G. P., 1993:Aust. J. Agric. Res.44, 179.

Deland, M. P. B., Malau-Aduli, A. E. O., Siebert, B. D., Bottema, C. D. K., Pitchford, W. S.,1998: Sex and breed differences in the fatty acid composition of muscle phospholipids in crossbred cattle. In: Proc. 6th World Congress on Genetics Applied to Livestock Production, Vol. 25,185.

Gilmour, A. R., Thompson, R., Cullis, B. R., Welham, S. J.1998:ASREML.User notes. New South Wales Agriculture, Orange, Australia (mimeo).

Griffin, T. L. C. \& McCaskill, M., 1987: Atlas of South Australia. Griffin Press Ltd.

Gurr, M. I. \& Harwood, J. L., 1991: Lipid Biochemistry: An Introduction. Chapman and Hall, London UK

Harvey, W. R., 1990: Mixed model least-squares and maximum likelihood computer program LSMLMW, Pc-2 version, User Guide.

Hecker, A. L., Cramer, A., Hugham, D. F.,1975: J. Food Sci.40,144.

Huerta-Leidenz, N. O., Cross, H. R., Savell, J. W., Lunt, D. K., Baker, J. F., Pelton, L. S., Smith, S. B.,1993:J. Anim. Sci.71, 625.

Huerta-Leidenz, N. O., Cross, H. R., Savell, J. W., Lunt, D. K., Baker, J. F., Smith, S. B.,1996: J. Anim. Sci.74,1256. 
Johnson, E. R., 1987: Meat Sci.20, 267.

Koots, K. R., Gipson, J. P., Wilton, J. W., 1994a: Anim. Breed. Abst. 62, 825.

Koots, K. R., Gipson, J. P., Smith, C., Wilton, J. W., 1994b: Anim. Breed. Abst.62, 309.

Litchfield, C., 1972: Analysis of Triglycerides. Academic Press, New York

Malau-Aduli, A. E. O., Siebert, B. D., Pitchford,W. S., Bottema, C. D. K.,1995:Proc.

Aust. Assoc. Anim. Breed. Genet. 11, 554.

Malau-Aduli, A. E. O., Siebert, B. D., Bottema, C. D. K., Pitchford, W. S., 1996: Genetic comparison of the fatty acid composition of intramuscular fat of early and late -maturing cattle breeds. In: Proc. 8th Animal Science Congress, Asian-Australasian Society of Animal Production, Tokyo, Japan, Vol. 2, 32.

Malau-Aduli, A. E. O., Siebert, B. D., Bottema, C. D. K., Pitchford,W. S.,1997a:Aust. J. Agric. Res.48,715.

Malau-Aduli, A. E. O., Siebert, B. D., Bottema, C. D. K., Pitchford,W. S.,1997b:Proc. Assoc. Advancement Anim. Breed. Genet. 12, 580.

Malau-Aduli, A. E. O., 1998: Genetic variation in fatty acid composition of cattle breeds. $\mathrm{PhD}$ Thesis, University of Adelaide, Australia

Malau-Aduli, A. E. O., Siebert, B. D., Deland, M. P. B., Bottema, C. D. K., Pitchford,W. S., 1998a:Heritabilities of triacylgly cerol fatty acids from the adipose tissue of beef cattle at weaning and slaughter. In: Proc. 6th World Congress on Genetics Applied to Livestock Production, Vol. 25,181.

Malau-Aduli, A. E. O., Siebert, B. D., Bottema, C. D. K., Pitchford,W. S.,1998b:J. A nim. Sci.76,766.

Marshall, D. M., 1994: J. Anim. Sci.72, 2745.

Mohiuddin, G., 1993:Anim. Breed. Abst.61, 495.

Perry, D., Nicholls, P. J., Thompson, J. M., 1998: J. Anim. Sci.76, 87.

Rutley, D. L., Deland, M. P. B., Pitchford, W. S., 1995: Proc. Aust. Assoc. Anim. Breed. Genet.11, 151.

Siebert, B. D., Deland, M. P. B., Pitchford, W. S., 1996:Aust. J. Agric. Res.47, 943.

Siebert, B. D., Malau-Aduli, A. E. O., Bottema, C. D. K., Deland, M. P. B., Pitchford, W. S., 1998: Genetic variation between crossbred weaner calves in triacylglycerol fatty acid 
composition. In: Proc. 6th World Congress on Genetics Applied to Livestock Production , Vol. 25,177.

Thornton, R. F., Shaw, F. D., Hood, R. L., 1974:Aust. J. Exp. Agric. Husbandry 14, 281.

Authors' addresses: A. E. O. Malau-Aduli, National Animal Production Research Institute, Ahmadu Bello University, P.M.B. 1096 Zaria, Nigeria; M. A. Edriss, Animal Science Department, College of Agriculture, Isfahan University of Technology, Isfahan, Iran; B. D. Siebert, C. D. K. Bottema and W. S. Pitchford, Department of Animal Science, University of Adelaide, Waite Agricultural Research Institute, Glen Osmond SA 5064, Australia 
Table 1. Data structure of pedigree file and in different years

Total number of animals

Total number of sires

Total number of dams

Average dams/sire

Average progeny/dam

Average progeny/sire

Number slaughtered in 1994

Number slaughtered in 1995

Number slaughtered in 1996
764

76

485

6.38

1.58

10.05

312

316

136 
Table 2. Descriptions of unadjusted data for the traits considered

\begin{tabular}{lrrrr} 
Trxits & Minimum & Masimum & Mean & SD \\
\hline Melting point & 30.00 & 50.00 & 39.28 & 3.42 \\
Marbling & 1.00 & 3.00 & 1.09 & 0.67 \\
C16:0 & 23.40 & 50.90 & 29.59 & 2.68 \\
C18:0 & 11.97 & 23.30 & 13.50 & 2.77 \\
C18:1n9 & 32.10 & 56.51 & 40.99 & 4.12 \\
SFA & 43.67 & 77.25 & 47.22 & 3.83 \\
MUFA & 42.24 & 61.31 & 51.00 & 3.82 \\
PUFA & 0.26 & 3.29 & 1.67 & 0.63 \\
Desaturation index (C16) & 9.80 & 25.45 & 13.92 & 3.02 \\
Desaturation index (C18) & 57.17 & 86.34 & 75.21 & 5.69 \\
Elongation index & 59.40 & 73.27 & 61.24 & 4.03
\end{tabular}

SFA (saturated fatty acids) $=\mathrm{C} 14: 0+\mathrm{C} 16: 0+\mathrm{C} 17: 0+\mathrm{C} 18: 0$

MUFA (mono-unsaturated fatty acids) $=\mathrm{C} 14: 1+\mathrm{C} 16: 1+\mathrm{C} 17: 1+\mathrm{C} 18: 1 \mathrm{n}-9+\mathrm{C} 18: 1 \mathrm{n}-7$

PUFA (polyunsaturated fatty acids) $=\mathrm{C} 18: 2$

Desaturation index $(\mathrm{C} 16)=100[(\mathrm{C} 16: 1) /(\mathrm{Cl} 16: 0+\mathrm{C} 16: 1)]$

Desaturation index $(\mathrm{C} 18)=100[(\mathrm{C} 18 ; 0)(\mathrm{C} 18 ; 0+\mathrm{C} 18: 1 \mathrm{n}-9)]$

Elongation $=100[(\mathrm{C} 18: 0+\mathrm{C} 18: 1 \mathrm{n}-9) /(\mathrm{C} 16: 0+\mathrm{C} 16: 1+\mathrm{C} 18: 0+\mathrm{C} 18: 1 \mathrm{n}-9)]$ 
Table 3. Least-squares means $\pm \mathrm{SE}$ of considered traits

\begin{tabular}{|c|c|c|c|c|c|c|c|c|c|c|c|}
\hline & $\frac{N a}{N_{n}}$ & $\begin{array}{l}\text { Malies } \\
\text { podx }\end{array}$ & Matliny & Pikiuse & swares & Chus & STK & sura & 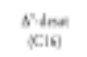 & $\begin{array}{l}\text { Sileat } \\
\text { X:15 }\end{array}$ & Elegyasaa \\
\hline $\begin{array}{l}\text { Ovenal nous } \\
\text { finc-kred }\end{array}$ & 74 & $19, + \pm 0,-47$ & $1,07 \pm 0.56$ & $\frac{206 \pm 0.35}{\mathrm{N5}}$ & $13.5 \pm 0.11$ & $+1.8 \pm 0.32$ & $\frac{6.2 \pm 0.38}{\mathrm{~N} 5}$ & $529 \pm 0.53$ & $13.9 \pm 0.3$ & Ral $1 \pm 0$ & $61.2 \pm 0.4$ \\
\hline Angas & 184 & $396+0,12$ & $1.25+0.67$ & $29.9+0.38$ & $135+0.26$ & $0.6+0.43$ & $0.6+6.47$ & $50.8+8.44$ & $134+0.29$ & $74.7+0.5$ & $61.6+04$ \\
\hline Bdoun blas & in & $150=0.36$ & $0.87 \pm 0.66$ & $20.5 \pm 0.25$ & $135 \pm 0.24$ & $41.8 \pm 0+1$ & $6.0 \pm 0.42$ & $51.1 \pm 2,+1$ & $140 \pm 0.27$ & $74,9 \pm 0.3$ & $61.2 \pm 03$ \\
\hline Herdond & 9 & $395=0.41$ & $1.05+0.07$ & $29.5+0.31$ & $14.0+0.27$ & $0.5+0.47$ & $0.6+0.49$ & $526+0.47$ & $13.4+0.31$ & $74.9+0.6$ & $61.4+2.4$ \\
\hline Jency & 122 & $373=0.37$ & $134+0.86$ & $1904 \pm 0.26$ & $12.3 \pm 0.24$ & $0.3+0.10$ & 46) $3+44$ & $521+3.42$ & $159+0.27$ & $770 \pm 0.5$ & $60.4 \pm 03$ \\
\hline timasis & ili & $408=0.4$ & $\mathrm{BS}+0.6$ & $2 x+40.77$ & $1+0+0.14$ & $+10+0+0$ & $40.5+0.3$ & $36+0+1$ & $193+0.77$ & $746+09$ & $61.7+0$. \\
\hline Scuth Drron & 184 & $405 \geq 0.3 ?$ & $0.94 \pm 0.56$ & $2 n \leq \pm 0.3$ & $16.1 \pm 0.19$ & $0.9 \pm 0.42$ & $4.5 \pm 2.44$ & $52.4 \pm 0.43$ & $13.4 \pm 0.25$ & $74.9 \pm 0.9$ & 61.4t03 \\
\hline $\mathrm{X}_{\text {wav }}$ & 115 & $38.1=0.37$ & $1.20+0.66$ & $2007 \pm 0.28$ & $13.1+0.24$ & $4.3+0.40$ & $46+6.4$ & $51.2+6.11$ & $19.9+0.27$ & $7,9+0.5$ & $61.2+43$ \\
\hline 5ex by yar & & w & $n$ & $n$ & $n$ & $n$ & $n$ & "s & $\omega$ & no & $\omega$ \\
\hline shor, 1904 & 162 & $39.1=0.24$ & $1.22 \pm 0.55$ & $31,1 \pm 0.31$ & $12.5 \pm 0.19$ & $+1.5 \pm 0.31$ & $-8,5 \pm 0.33$ & $248 \pm 0.38$ & $14+ \pm 0.22$ & $x+3 \pm 0$. & $3 \times 6 \pm 0.3$ \\
\hline Hefor, $19 \%$ & 190 & $40.3=0.23$ & $1.8+2=5$ & $20+202$ & $134+0.20$ & $\begin{array}{r}42.3+034 \\
\end{array}$ & 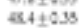 & $521+0.44$ & $115 \pm 0.22$ & $7 x+2.4$ & $6 \mathrm{~S}+ \pm 03$ \\
\hline Skar, 1965 & 17 & $4.5=0.27$ & $1.14 \pm 0.65$ & $19.2 \pm 0.21$ & $14.5 \pm 0.19$ & $00 \pm 0.4 t$ & $0.9+0.36$ & $506+3.42$ & $133+0.21$ & $734 \pm 04$ & $61.8+0.3$ \\
\hline Hefief, IOW & (14) & $173=0.39$ & $0,2+0,3$ & $8 x 9+0.21$ & $11.9+0.10$ & $m s+0.45$ & $46+6.3$ & $521+0.4$ & $161+0.25$ & $7 \mathrm{k}^{3}+2 \mathrm{t}$ & nutas \\
\hline Hefor, $1 \% \pi$ & 136 & $3 x=0.32$ & $1.01 \pm 0.5$ & $20.2 \pm 0.23$ & $130 \pm 021$ & $41.6 \pm 0.46$ & $45 \pm 0.36$ & $31.2 \pm 0.38$ & $140 \pm 0.23$ & Tha+14 & $61.9+03$ \\
\hline
\end{tabular}

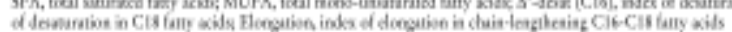


Table 4. Heritabilities of different traits

\begin{tabular}{lc} 
Traits & $\begin{array}{c}\text { Heritability } \\
\text { estimate }\end{array}$ \\
\hline Melting point & $0.27 \pm 0.10$ \\
Marbling & $0.09 \pm 0.08$ \\
C16:0 & $0.13 \pm 0.08$ \\
C18:0 & $0.12 \pm 0.08$ \\
C18: 1n9 & $0.05 \pm 0.07$ \\
SFA & $0.22 \pm 0.06$ \\
MUFA & $0.14 \pm 0.01$ \\
Desaturation index (C16) & $0.13 \pm 0.08$ \\
Desaturation index (C18) & $0.19 \pm 0.02$ \\
Elongation & $0.10 \pm 0.08$ \\
SFA, saturated fatty acids; MUFA, mono-unsaturated \\
fatty acids
\end{tabular}


Table 5. Phenotypic and genetic correlations of melting point and marbling with other traits

\begin{tabular}{|c|c|c|c|c|}
\hline & \multicolumn{2}{|c|}{ Melting point } & \multicolumn{2}{|c|}{ Marbling } \\
\hline & Phenotypic & Genetic & Phenotypic & Genetic \\
\hline $\mathrm{C} 16=0$ & $0.20 \pm 0.04$ & $0.26 \pm 0.33$ & $0.03 \pm 0.04$ & $-0.11 \pm 0.52$ \\
\hline C18:0 & $0.41+0.03$ & $0.62+0.26$ & $-0.08+0.03$ & $-0.71+0.52$ \\
\hline C18:1n9 & $-0.21 \pm 0.04$ & $0.33 \pm 0.58$ & $-0.02 \pm 0.03$ & $0.37 \pm 0.80$ \\
\hline SFA & $0.41 \pm 0.03$ & $0.36 \pm 0.29$ & $-0.01 \pm 0.04$ & $-0.42 \pm 0.43$ \\
\hline MUFA & $-0.36 \pm 0.03$ & $-0.38 \pm 0.29$ & $0.02 \pm 0.04$ & $0.45 \pm 0.50$ \\
\hline Desaturation index (C16) & $0.40 \pm 0.04$ & $0.93 \pm 0.59$ & $0.09 \pm 0.04$ & $0.46 \pm 0.56$ \\
\hline Desaturation index (CI8) & $0.35 \pm 0.03$ & $0.14 \pm 0.17$ & $0.06 \pm 0.02$ & $0.60 \pm 0.36$ \\
\hline Elongation index & $-0.03 \pm 0.04$ & $0.39 \pm 0.47$ & $-0.06 \pm 0.04$ & $-0.01 \pm 0.59$ \\
\hline
\end{tabular}

SFA, saturated fatty acids; MUFA, mono-unsaturated fatty acids 
Table 6. Phenotypic and genetic correlation between some other traits

\begin{tabular}{lrr} 
Traits under analysis & \multicolumn{1}{c}{ Phenotypic } & \multicolumn{1}{c}{ Genetic } \\
\hline Melting point and marbling & $-0.04 \pm 0.03$ & $-0.48 \pm 0.40$ \\
C16:0 and C18:0 & $-0.06 \pm 0.03$ & $0.67 \pm 0.50$ \\
C16:0 and C18: $1 \mathrm{n} 9$ & $-0.63 \pm 0.02$ & $-1.00 \pm 0.40$ \\
C18:0 and C18: 1n9 & $-0.14 \pm 0.03$ & $-0.81 \pm 0.71$ \\
SFA and MUFA & $-1.00 \pm 0.33$ & $-1.00 \pm 0.12$ \\
Desaturation index (C16) and Desaturation index (C18) & $0.52 \pm 0.02$ & $0.53 \pm 0.22$ \\
Desaturation index (C16) and Elongation index & $0.27 \pm 0.03$ & $0.09 \pm 0.59$ \\
Desaturation index (C18) and Elongation index & $0.21 \pm 0.02$ & $0.76 \pm 0.45$
\end{tabular}

SFA, saturated fatty acids; MUFA, mono-unsaturated fatty acids 